\title{
CONSTRUCCIÓN DE COALICIONES ELECTORALES EN ESCENARIOS DESNACIONALIZADOS. UN APORTE TEÓRICO
}

\author{
Construction of electoral coalitions \\ in denationalized scenarios. \\ A theoretical approach
}

\author{
FACUNDO CRUZ \\ Universidad Argentina de la Empresa \\ Universidad de Buenos Aires \\ cruzfacu@gmail.com
}

Cómo citar/Citation

Cruz, F. (2019).

Construcción de coaliciones electorales en escenarios desnacionalizados. Un aporte teórico. Revista de Estudios Políticos, 184, 161-194. doi: https://doi.org/10.18042/cepc/rep.184.06

\section{Resumen}

En escenarios de fragmentación y desnacionalización partidaria como los que se generaron en las últimas dos décadas en América Latina, la fórmula política privilegiada por los dirigentes partidarios ha sido la de conformar coaliciones electorales. Son acuerdos que se conforman a partir de las decisiones estratégicas de las elites partidarias. En sistemas políticos multinivel pueden ser estudiados como etapas de una construcción que conforman un castillo de naipes (house of cards): cada partido político representa una carta, que se va conectando con otras y armando los niveles superiores para continuar la construcción. Este artículo busca suplir una laguna en el estudio de estos fenómenos, proponiendo un marco teórico que resulte provechoso para su análisis. Entiendo que las coaliciones electorales se forman por penetración territorial desde un centro político que establezca pautas, condiciones y tiempos del acuerdo político; o por difusión territorial entre partidos que ya se encuentran presentes en gran parte del territorio. Establezco los lineamientos generales de la teoría, los incentivos y las limitaciones que surgen. La construcción teórica se plantea desde un caso de estudio (Argentina, 1983-2015), pero con pretensiones de ser aplicada a otros sistemas políticos multinivel similares. 


\title{
Palabras clave
}

Coaliciones electorales; política multinivel; process tracing; partidos políticos.

\begin{abstract}
In scenarios of party fragmentation and denationalization, such as those generated in the last two decades in Latin America, the political formula privileged by party leaders has been the formation of electoral coalitions. These are agreements constructed and based on the strategic decisions of the party elites. In multi-level political systems, they can be studied as stages of building a house of cards: each political party represents a card, which is connected to others and establishes the bases of upper levels to continue the construction process. This article seeks to fill a gap in the study of these phenomena, proposing a theoretical framework that is useful for its analysis. I understand electoral coalitions as being formed either following a 'territorial penetration strategy', from a political centre that establishes guidelines, conditions and timings of the political agreement; or by a 'territorial diffusion strategy' between parties that are already present in a large part of the territory. I establish the general guidelines of the theory, along with the incentives and the limitations that arise. The theoretical construction is considered in relation to a case study of Argentina (1983-2015), highlighting its potential to be applied to other similar multilevel political systems.
\end{abstract}

\section{Keywords}

Electoral coalitions; multilevel politics; process tracing; political parties. 


\section{SUMARIO}

I. INTRODUCCIÓN. II. ¿̇POR QUÉ ES UN TEMA RELEVANTE? ILUSTRACIÓN A PARTIR DEL CASO ARGENTINO, 1983-2015. III. DESNACIONALIZACIÓN Y COALICIONES ELECTORALES MULTINIVEL. IV. APORTES TEÓRICOS PARA EL ESTUDIO DE LAS COALICIONES ELECTORALES MULTINIVEL. V. INCENTIVOS Y PROBLEMAS PARA EL PROCESO DE CONSTRUCCIÓN COALICIONAL. VI. CONCLUSIONES. BibLIOGRAFÍA.

\section{INTRODUCCIÓN}

Las coaliciones electorales se construyen a partir de las decisiones estratégicas de las elites partidarias. En sistemas políticos multinivel estos procesos pueden ser entendidos como un castillo de naipes (house of cards): las cartas se van uniendo, apoyadas unas en otras y permitiendo que se apilen en niveles unas arribas de otras hasta terminar de formar la pirámide.

¿Por qué resulta relevante la problemática planteada? Porque los partidos políticos son organizaciones relativamente estables, pero interactúan entre sí en ambientes cambiantes: los sistemas de partidos que integran suelen modificar sus patrones de competencia y, a veces, su formato. Este espacio en el que se insertan y que ellos mismos le dan forma se altera, se modifica, evoluciona, avanza y retrocede (a veces, aunque poco). Estos cambios en los patrones de competencia en América Latina han sido analizados por diversos trabajos (Jones y Mainwaring, 2003; Morgenstern et al., 2009; Freidenberg y Suárez Cao, 2014; Torcal, 2015; Freidenberg, 2016a, 2016b; Morgenstern, 2017; Mainwaring, 2018). Así, los sistemas partidarios se han fragmentado más (aumento de competidores) y lo han hecho de manera diferenciada en sus provincias, estados y/o departamentos (desnacionalización).

Adicionalmente, los Estados federales se caracterizan por adoptar una forma particular en el interior de la cual se genera una interacción entre varios sistemas de partidos: uno que se genera a nivel nacional entre los partidos políticos nacionales y otros a nivel subnacional, tantos como unidades políticas lo integren (Swenden y Maddens, 2009; Gibson y Suárez Cao, 2010; Došek y Freidenberg, 2013; Escolar, 2014b y 2014c), formado por las suborganizaciones partidarias provinciales de los partidos nacionales y por partidos estrictamente de carácter provincial o local. Por ejemplo, en Argentina se cuenta un total de veinticinco sistemas de partidos si sumamos las 
veinticuatro provincias y el sistema de partidos nacional. Cada uno de ellos tiene dinámica propia, sus propias pautas de interacción y sus propias lógicas de funcionamiento.

Dado que los partidos políticos tienen como fin último sobrevivir como organizaciones políticas (Panebianco, 1990; Mair y Katz, 2015), buscan hacerlo a través del enfrentamiento entre sí, pero también estableciendo acuerdos. Esto se produce dentro de un proceso en el cual se reparten los limitados recursos disponibles: los cargos públicos se dirimen en elecciones libres, obligatorias y limpias. El problema que surge es el siguiente: ¿qué ocurre cuando los que compiten son muchos? ¿Cómo pueden sobrevivir si lo disponible para repartir es limitado? Si los partidos políticos tienen objetivos similares, pero los escenarios en los que compiten son cambiantes y distintos, entonces surge un fenómeno político interesante para ser abordado en profundidad en términos teóricos. ¿Cómo pueden hacer para acceder a una cantidad de cargos públicos limitados? Si todos no tienen la misma fortaleza electoral para hacerlo, ¿cuál es la clave para alcanzar sus objetivos organizacionales? Acordar. Consensuar. Construir coaliciones electorales. Sumar tantos naipes como sean necesarios para formar una pirámide.

Las coaliciones electorales pueden ser entendidas como un subtipo de las coaliciones políticas en sistemas presidenciales (Cruz y Clerici, 2015): son los casos de estudios específicos sobre acuerdos entre partidos que deciden competir en elecciones y que adquieren determinadas características. El estudio de este fenómeno en América Latina ha arrojado una provechosa producción académica en los últimos veinte años ${ }^{1}$. La mayoría de los mencionados, sin embargo, se han centrado en la dimensión de gobierno de las coaliciones políticas. Recientemente, a partir de la importancia que ha adquirido el estudio de la política subnacional en la región (Došek y Freidenberg, 2013; Suárez Cao et al., 2017), los trabajos sobre coaliciones desde una perspectiva multinivel han traído la dimensión electoral al centro de la escena y se han convertido en un tema de notable interés para académicos de distintas procedencias, con distintos casos de estudio y desde distintas estrategias de investigación ${ }^{2}$. Esta

1 Entre los más destacados resaltan Flisfisch (1990), Deheza (1998), Zelaznik (2001), Altman (2000), Cheibub et al. (2004), Amorim Neto (2006), Serrafero (2006), Chasquetti (2008), Reniu (2008), Albala (2016, 2017), Reniu y Albala (2012) y Clerici et al. (2016).

2 Cabe resaltar los siguientes: Samuels (2000), Kinzo (2003), Lyne (2008), Braga (2006), Machado (2009), Krause et al. (2010), Reynoso (2011), Clerici (2015, 2016, 2017, 2018), Clerici y Scherlis (2014), Miño (2014), Clerici et al. (2016), Krause et al. (2016), Devoto y Olmeda (2017), Reynoso y Espinosa Santiago (2017) y Cruz (2019). 
provechosa agenda de investigación ha sido enmarcada dentro de la cuarta generación de estudios sobre el tema (Clerici et al., 2018).

Ahora bien, persiste una limitación en la investigación sobre coaliciones electorales multinivel y es el desarrollo de una teoría que plantee premisas generales para comprender su proceso de construcción. El armado de los acuerdos entre partidos políticos para competir en elecciones aún carece de un marco teórico sólido y conciso que caracterice el tipo de actores que lo conforman, los posibles resultados del proceso, y que funcione como un marco general de estudio sobre el tema. Concretamente, ¿cómo es el proceso de construcción de una coalición electoral multinivel? ¿Bajo qué condiciones deciden construir determinados acuerdos electorales? ¿Qué partidos políticos la integran? ¿Cuáles son las estrategias que persiguen y los recursos que disponen para alcanzar sus objetivos? ¿Cuáles son las reglas que acuerdan para intentar alcanzar los acuerdos a los que llegan?

Estos acuerdos cooperativos entre actores que dan forma a las coaliciones pueden hacerse por penetración territorial o por difusión territorial (Panebianco, 1990). El primer modelo de construcción se caracteriza por un centro político que controla todo el proceso. Aquí hay un grupo de dirigentes que representa a una sola o unas pocas unidades políticas (provincia, estado o departamento), que son quienes toman las decisiones centrales en torno a nombres, logos y candidaturas, y que fijan las reglas de la cooperación. Además de eso, la estructura política con la que hacen el acuerdo tiene un grado de concentración regional alta: no está muy extendido en el territorio. Salen desde un distrito hacia el resto del país. Lo cual, en cierta medida, los obliga a buscar aliados en la mayoría de las provincias del país.

El segundo modelo es el polo opuesto. En este caso, los dirigentes que toman las decisiones son más representativos de varias provincias y la estructura con la que impulsan la construcción coalicional está más diseminada. Adicionalmente, no suele haber un grado de control tan alto de esta mesa directiva sobre el proceso: si bien establecen algunos criterios generales para la conformación de los acuerdos en las provincias en torno a aliados y candidaturas, hay un mayor reparto del peso decisor entre los líderes nacionales y los referentes provinciales.

En este artículo planteo un marco teórico que profundiza sobre estas cuestiones y que resulta útil para estudiar los procesos de formación de coaliciones electorales en sistemas partidarios multinivel. A partir de la experiencia de investigación realizada sobre el caso de Argentina entre 1983 y 2015, desarrollo algunas premisas teóricas generales que pueden cubrir la laguna detectada en este subárea temática de la política comparada. Cabe aclarar que, si bien los datos aportados son extraídos de un único caso de estudio en América 
Latina, la teoría que desarrollo tiene pretensiones de generalización y puede ser aplicado a otros sistemas políticos multinivel ${ }^{3}$.

El escrito se organiza de la siguiente manera. En primer lugar, destaco algunos elementos empíricos que resultan importantes para comprender por qué resulta necesario proponer una teoría al respecto. Esto se centra en el estudio del sistema partidario argentino en el período definido anteriormente. En segundo lugar, planteo la construcción de coaliciones electorales como consecuencia de la desnacionalización del sistema partidario. En tercer lugar, desarrollo el marco teórico propuesto. En cuarto lugar, preciso los incentivos que los unen y las complicaciones que surgen del proceso coalicional. Finalmente, sintetizo los principales aportes en las conclusiones.

\section{II. ¿̇POR QUÉ ES UN TEMA RELEVANTE? ILUSTRACIÓN A PARTIR DEL CASO ARGENTINO (1983-2015)}

Aquellos dirigentes, candidatos o funcionarios que desean convertirse en, por ejemplo, presidente, necesitan encontrar aliados en la mayor cantidad de provincias posibles que pongan a disposición sus recursos en pos de un acuerdo que le garantice beneficios y ventajas a todos los involucrados. Adicionalmente, quienes «hacen política» en las provincias necesitan de apoyos en el nivel nacional para disponer de recursos públicos que les permitan gobernar (si ocupan la gobernación) o bien ganarla (si ocupan el rol de oposición provincial). En medio de esta interacción, los presidentes también precisan legisladores que voten sus propuestas en el Congreso Nacional, siendo estos electos en cada uno de los distritos del país. Estas interacciones políticas adquieren una dinámica particular: una dinámica coalicional. Son acuerdos relativamente estables entre actores partidarios que buscan alcanzar un objetivo común y acordado entre ellos, para lo cual cada uno pone a disposición determinados recursos políticos necesarios. Si cada partido político es un naipe que forma la base para el nivel superior de construcción, entonces la clave radica en que sea una unión lo suficientemente sólida para que las partes superiores no se tambaleen.

3 El caso argentino puede ser considerado como extremo en la clasificación que realiza Gerring (2010) sobre estrategias de selección de estudios de caso, los cuales resultan útiles para testar hipótesis empíricas. Este artículo resultará de utilidad en el futuro para esos fines al ser un aporte teórico para el estudio de la construcción coalicional alternativo al utilizado en estudios europeos (bottom up y top down según el consenso académico. Una discusión al respecto se puede encontrar en Cruz, 2014). 
Este proceso adquiere mayor importancia cuando el sistema partidario se desnacionaliza. En otras palabras, las elites partidarias tienen importantes incentivos para construir coaliciones electorales multinivel cuando la competencia política no es homogénea en los distritos o para los distintos cargos públicos en juego (Calvo y Escolar, 2005; Leiras, 2007; Gibson y Suárez Cao, 2010; Navarro y Varetto, 2014). En términos teóricos, la bibliografía especializada identifica dos polos bien diferenciados en el continuum nacionalizacióndesnacionalización (Jones y Mainwaring, 2003; Caramani, 2004; Chhiber y Kollman, 2004). Por nacionalización entiendo que la dinámica competitiva del sistema partidario es similar en múltiples niveles del sistema político: tanto en cada uno de los distritos (provincias, estados o departamentos) como entre el nivel subnacional y el nivel nacional. Esto presupone que hay una interacción entre sistemas partidarios subnacionales y nacionales (Gibson y Suárez Cao, 2010). En contraposición, la desnacionalización o «territorialización» de la política partidaria es el proceso a través del cual los patrones de competencia partidaria adquieren componentes provinciales o locales, haciendo que cada uno de los distritos que componen un estado tenga características propias y distintivas tanto de otros distritos como del nivel de competencia nacional. De esta forma, hay diferencias entre los sistemas partidarios subnacionales y el nacional, principalmente en su formato y en su dinámica competitiva.

Argentina no ha escapado a este proceso. Los primeros estudios que analizaron el proceso de desnacionalización de la política partidaria lo hicieron desde una perspectiva temporal, destacando los momentos en los cuales progresivamente el sistema partidario argentino iba perdiendo su componente bipartidista tradicional y se dirigía hacia un polo más «territorializado» de la competencia electoral. Distingo cuatro etapas, en consonancia con lo planteado por Navarro y Varetto (2014). La primera refiere al período que comprende las primeras elecciones desde el retorno a la democracia en 1983 y se extiende hasta los primeros años de la década de los noventa. Durante estos ańos, tanto el Partido Justicialista (PJ) como la Unión Cívica Radical (UCR) dominaron el escenario partidario nacional y los provinciales, alcanzaron altas proporciones de votos entre ambos y se repartieron los principales cargos en juego —ejecutivos y legislativos de todos los niveles del sistema- (De Riz y Adrogué, 1991).

Una segunda etapa se abre con las elecciones legislativas de 1991 hasta el triunfo de la Alianza ${ }^{4}$ en las elecciones de 1997 y 1999. Durante este período

4 La Alianza para el Trabajo, la Justicia y la Educación fue una coalición electoral que al ganar las elecciones presidenciales de 1999 devino en coalición de gobierno. Estuvo integrada por la Unión Cívica Radical (UCR), el FREPASO (Frente País Solidario) y 
se puede percibir un leve aumento en la fragmentación del sistema partidario y la aparición temprana de nuevos actores del sistema (MODIN, Frente Grande/FREPASO), sumado a la consolidación de partidos provinciales (Movimiento Popular Neuquino, Partido Bloquista en San Juan, Fuerza Republicana en Tucumán, por mencionar algunos). Este leve aumento en la fragmentación partidaria se manifestó, sin embargo, en unas pocas provincias argentinas (Malamud y De Luca, 2016), sin que se produjera en paralelo una marcada tendencia hacia la "provincialización». Sí, en cambio, hubo un anticipo o «esbozo» de un fenómeno que se manifestaría con más fuerza diez años más tarde (Navarro y Varetto, 2014).

La tercera etapa del sistema partidario argentino abarca los años que cubre el surgimiento, auge y caída de la Alianza. Durante esos años, la dinámica competitiva adquirió componentes bipolares similares a los que caracterizaron el bipartidismo peronista-radical de la década de los ochenta, lo cual moderó transitoriamente el impulso hacia la fragmentación que se había iniciado en la etapa anterior. Este período ha sido caracterizado como «la ilusión de la Alianza» (Calvo y Escolar, 2005), en tanto la construcción de la coalición electoral solo dilató (transitoriamente) un proceso de transformación del sistema partidario que ya estaba mostrando las primeras señales de desnacionalización y «territorialización» de la competencia partidaria. En esta tercera etapa la competencia partidaria se torna abierta e impredecible (Abal Medina y Suárez Cao, 2002). Otros autores, en cambio, consideran que durante estas tres etapas (desde 1983 hasta fines de la década de los noventa) el sistema partidario argentino no sufrió alteraciones drásticas en su dinámica competitiva ni en su nivel de fragmentación (Malamud y De Luca, 2016).

Gibson y Suárez Cao (2010), en cambio, ven en las elecciones celebradas en 1999 el primer indicio importante de desnacionalización del sistema partidario argentino. Al medir la incongruencia del sistema federalizado de partidos ${ }^{5}$ encuentran que el primer salto en el índice se da entre 1995 y 1999,

otros partidos menores de distrito de tendencia de centro-izquierda. La finalización abrupta de su mandato coincidió con un espiral de crisis que impactó en gran medida en múltiples ámbitos de la vida pública y privada de los argentinos. Para un análisis del caso en perspectiva comparada (con una hipótesis sobre las causas de su fracaso como coalición de gobierno) véase Cruz (2010).

5 Gibson y Suárez Cao (2010) consideran que un sistema federalizado de partidos es congruente cuando los valores de NEP son similares al comparar el nivel nacional con el nivel provincial. Es incongruente, en cambio, cuando hay valores distintos tanto entre el nivel nacional y el provincial, como entre los sistemas partidarios provinciales. El Índice de Congruencia construido es una medida de las divergencias 
producto, mayormente, de la varianza entre los sistemas partidarios provinciales. De esta forma, la «ilusión de la Alianza» contuvo la fragmentación partidaria a nivel nacional, pero no evitó que los sistemas partidarios provinciales comenzaran a mostrar patrones de competencia distintos entre sí.

La cuarta etapa del sistema partidario argentino comienza con la caída del Gobierno de la Alianza a finales del 2001 y se extiende hasta la actualidad. En dicha etapa el fenómeno de la desnacionalización se hace mucho más marcado, no solo por las diferencias entre los patrones de competencia nacional y provincial, sino también por la creciente variación en las dinámicas competitivas de cada uno de los distritos (Gibson y Suárez Cao, 2010) ${ }^{6}$. En esta nueva etapa del sistema partidario argentino la principal atracción para los partidos políticos son las provincias. Tal es así que a) estos distritos se convierten en la base de poder político de los partidos políticos; b) los caudillos provinciales son los que administran el acceso de cargos públicos y los mecanismos de financiamiento, y c) son quienes impulsan la construcción de coaliciones electorales (Malamud, 2012). En otras palabras, el sistema partidario argentino aparece como "descentrado" y las provincias son «el ancla» de sus partes componentes (ibid.: 111). Para Calvo y Escolar (2005: 96) «en los últimos 20 años, el sistema político argentino se ha vuelto considerablemente más competitivo. [...] sin embargo, no se ha distribuido de modo homogéneo a lo largo del territorio».

Las etapas antes descritas se pueden apreciar al observar cuatro indicadores centrales. En primer lugar, la proporción de partidos que compiten en más de un distrito para la elección de diputados nacionales (Clerici, 2015). Dividiendo el período en los cuatro períodos marcados, la evolución es la siguiente: 0,35 en la primera etapa, 0,32 en la segunda, 0,25 en la tercera y 0,20 en la cuarta $^{7}$. De esta forma, con el correr de los años una menor cantidad de partidos políticos compitieron en más de un distrito para acceder a una banca en la Cámara de Diputados nacional. En segundo lugar, el Party Nationalization Score (PSNS), desarrollado por Jones y Mainwaring $(2003)^{8}$, muestra cómo

cuadradas (MSD por sus siglas en inglés). El mismo captura tanto la diferencia promedio entre el NEP a nivel nacional y los NEP provinciales como la varianza entre estos últimos.

6 Según Gibson y Suárez Cao (2010), en 1999 el valor de MSD fue de 1.12 (0.49 diferencia entre nivel nacional y promedio de provincias, y 0.62 de varianza a nivel provincial), en 2003 de 7.13 (5.52 y 1.61 respectivamente) y en 2007 de 5.38 (0.01 y 5.37 respectivamente).

7 El cálculo se hizo según los datos aportados por Clerici (2015).

8 El índice de Jones y Mainwaring (2003) es uno de los más utilizados para medir el nivel de nacionalización de un sistema partidario (Gibson y Suárez Cao, 2010). Se 
progresivamente el sistema partidario argentino se movió de un polo nacionalizado (valores cercanos a 1) hacia otro más desnacionalizado (valores cercaos a 0 ), tendencia que se acentuó a partir de las elecciones de mitad de mandato celebradas en octubre de 2001.

Ambos indicadores son un fiel reflejo del proceso de «territorialización» y «provincialización» de la política partidaria argentina. El gráfico 1 sintetiza esta evolución.

Gráfico 1. Evolución PSNS según elecciones para Cámara de Diputados, 1983-2015

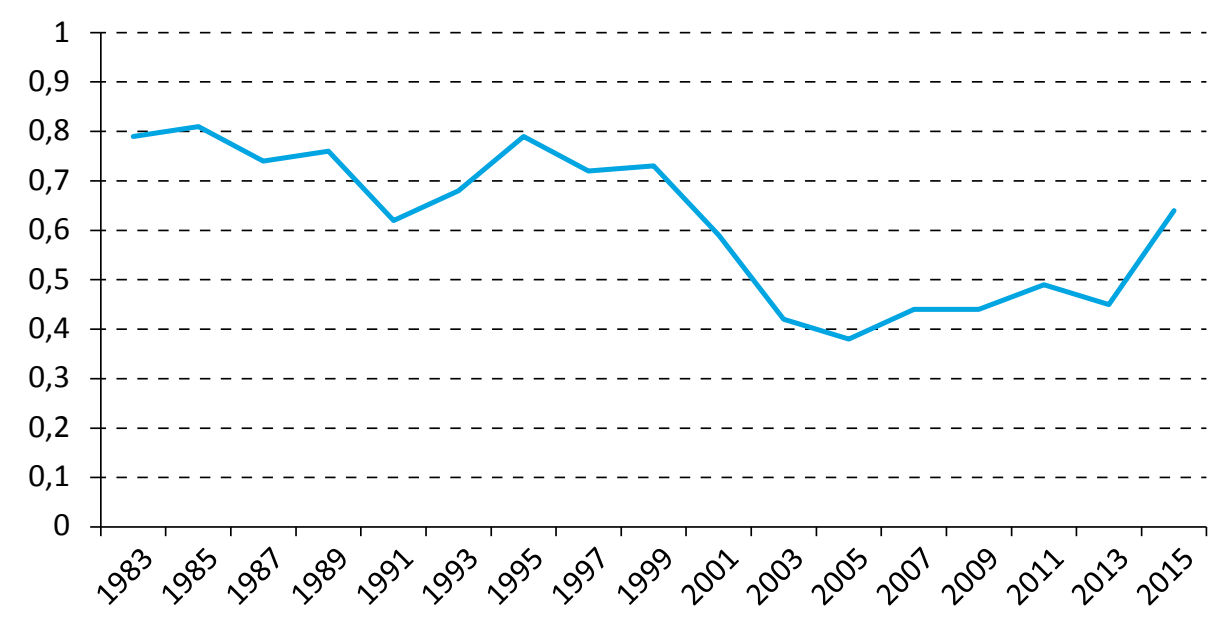

Fuente: elaboración propia en base a datos suministrados por Clerici (2015).

En tercer lugar, al observar el Número Efectivo de Partidos (NEP) ${ }^{9}$ para la competencia presidencial. El gráfico 2 muestra los valores de NEP desagregado en cada una de las provincias argentinas y también a nivel nacional desde 1983 hasta 2015.

Tal como se desprende del análisis de los datos, la crisis política, social, institucional y económica del 2001, junto con la caída de la Alianza como coalición de gobierno, produjo un impacto diferencial en la fragmentación partidaria provincial. Como un mero ejercicio de ejemplo, se puede prestar

calcula mediante la suma de los productos de los índices de nacionalización de cada partido (PNS) y su proporción nacional de votos. El PNS registra el nivel de nacionalización propio de cada partido. Es un coeficiente de Gini invertido.

9 Calculado a partir de Laakso y Taagepera (1979). 
atención a los casos de las provincias del sur y noreste del país en comparación a las más pobladas o urbanas del centro: el NEP presidencial sufrió alteraciones mucho menores en Santa Cruz, Chubut, Chaco o Formosa que en la Ciudad Autónoma de Buenos Aires, la provincia de Buenos Aires, Mendoza y Santa Fe. En este sentido, coincido con la literatura mencionada al destacar la menor competitividad electoral en algunas provincias y su aumento en otras.

Gráfico 2. NEP Presidencial a nivel nacional y provincial, 1983-2015

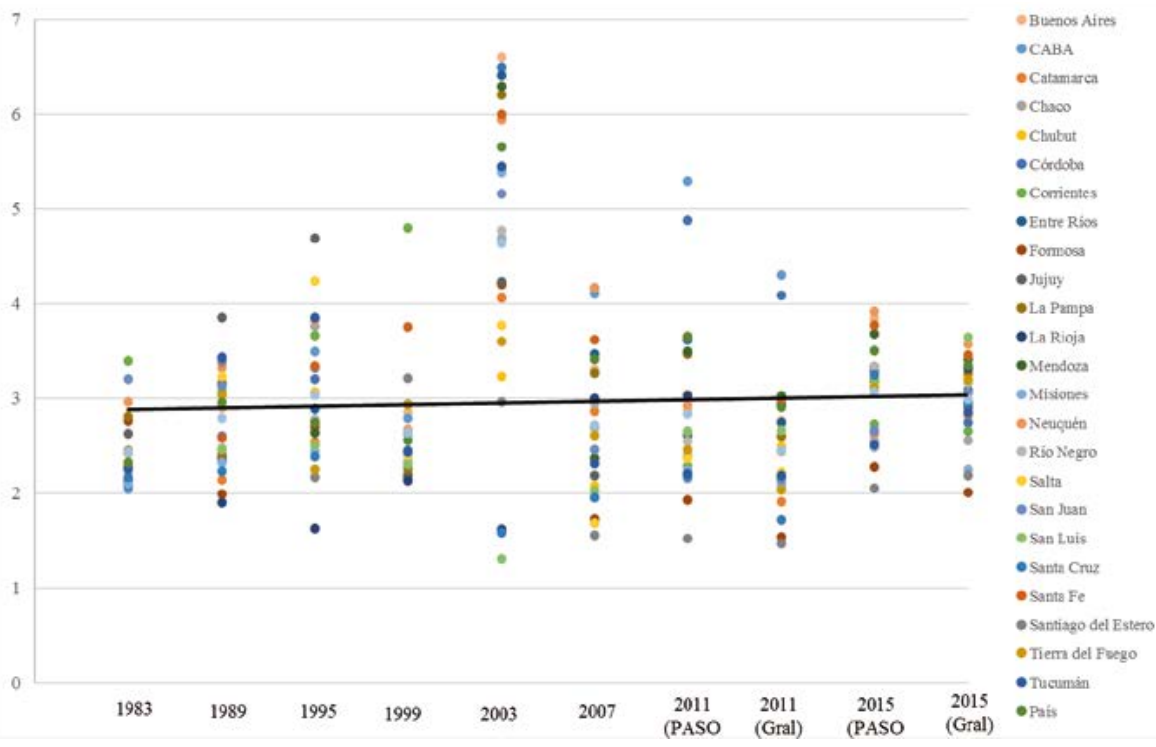

Fuente: elaboración propia en base a Andy Tow (http://www.andytow.com/blog/) y Calvo y Escolar (2005).

El cuarto y último indicador se centra en el análisis del NEP para el cargo de gobernador. El gráfico 3 sintetiza los valores para cada uno de los distritos durante el mismo período.

Al comparar ambos gráficos se desprende lo siguiente. Por un lado, el aumento de la cantidad de competidores presidenciales no fue en paralelo con una fragmentación tan marcada en la competencia por cargos provinciales en todos los distritos (dimensión vertical). Por otro lado, los cambios en el formato de competencia en cada uno de los distritos no se dieron de manera homogénea, sino que existieron provincias donde aumentó, otras donde se mantuvo y otras donde, incluso, se redujo la cantidad de 
competidores para gobernador (dimensión horizontal). Este choque de tendencias contrarias también ha sido denominado «fragmentación regionalmente desequilibrada» (FRD) (Navarro y Varetto, 2014). Estos autores ven este proceso como una secuencia causal de etapas que marcan la evolución del sistema partidario argentino hasta la actualidad, donde la FRD se ha «vuelto la norma» comúnmente aceptada. Las etapas de este proceso serían cuatro (2014: 122): a) persistencia de una estructura de competencia bipartidista en los primeros ańos del retorno a la democracia; b) erosión progresiva de la dinámica bipartidista desde las elecciones de 1999; c) fragmentación heterogénea según el tipo de jurisdicción (más pronunciada en provincias urbanas que en provincias menos pobladas), y d) impacto negativo de este nuevo escenario de competencia partidaria (FRD) en la integración vertical de la política partidaria argentina.

Gráfico 3. NEP Gobernadores desagregado por provincias, 1983-2015

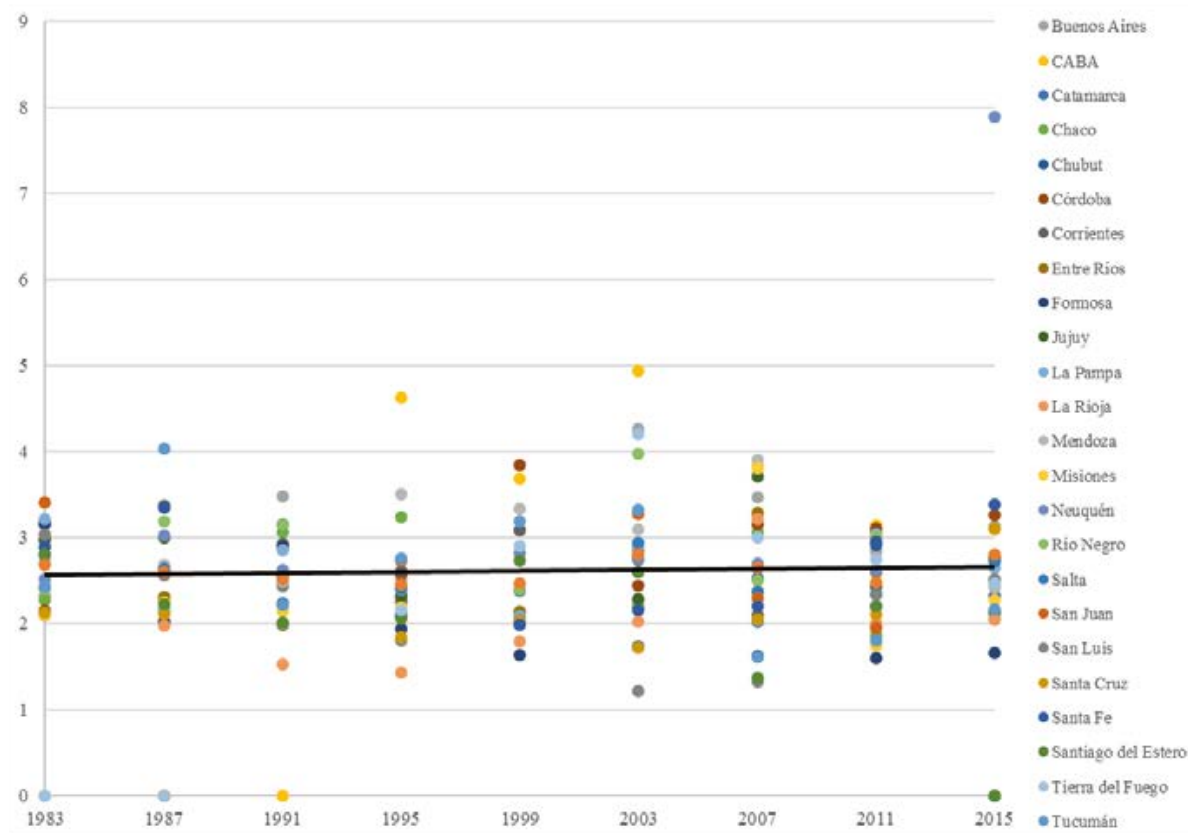

Fuente: elaboración propia en base a Andy Tow (http://www.andytow.com/blog/) y Calvo y Escolar (2005). 


\section{DESNACIONALIZACIÓN Y COALICIONES ELECTORALES MULTINIVEL}

¿Por qué el fenómeno de la desnacionalización partidaria guarda alguna relación con la construcción de coaliciones electorales multinivel? ¿Qué impacto tiene en este tipo de acuerdos políticos? Como bien indica Leiras (2007: 30), la desnacionalización partidaria «visto desde el punto de vista de algunas teorías del gobierno democrático aparece como una anomalía. Para tomar e implementar decisiones políticas hace falta formar coaliciones que las respalden». En un escenario de fragmentación partidaria, diferenciación regional de los patrones de competencia partidaria y dificultad para integrar verticalmente el «sistema federalizado de partidos», el desafío para los partidos políticos pasa por acordar, construir y (tratar de) mantener coaliciones electorales. Construir un castillo de naipes que les permita lograr sus propios objetivos políticos, individuales y compartidos.

La nueva dinámica competitiva generada por la evolución del sistema partidario argentino ha impactado, mayormente, en la construcción de coaliciones electorales a nivel nacional. En la competencia presidencial, la formación de una coalición electoral competitiva implica serios esfuerzos para coordinar «acuerdos de intercambio entre dirigentes de distintos niveles [de distintas organizaciones partidarias] que compiten en distintos distritos. El acuerdo consiste en la movilización de recursos electoralmente valiosos que controlan suborganizaciones partidarias autónomas a cambio de apoyo político, la cooperación financiera o la recompensa posterior que puede ofrecer el candidato ganador» (Leiras 2007: 121). Estas coaliciones «efímeras» (Escolar 2014a: 232) «son el resultado [...] del juego político no integrado de las elites nacionales, subnacionales y locales en cada unidad subestatal autogobernada que caracteriza el tipo de vinculación electoral [...]». En otras palabras, la unión entre las cartas y los niveles que forman para construir la pirámide no siempre se mantiene como tal, sino que cambian sus partes componentes. Esto ocurre debido a una serie de problemas no menores asociados a la desnacionalización partidaria ya mencionada.

En primer lugar, cada provincia argentina ha adquirido una dinámica competitiva particular y única. Tal como indiqué anteriormente, mientras que en algunas provincias el formato de competencia se mantuvo o se redujo, en otras ha aumentado con el correr de los años. Paralelamente, los partidos políticos que compiten en un distrito no necesariamente tienen presencia en todos $o$, incluso, en otros pocos. Esto ha dificultado seriamente que las coaliciones electorales tengan un alto nivel de integración y congruencia (Clerici, 2015).

En segundo lugar, la evolución del sistema partidario argentino ha producido un impacto en las estrategias electorales de los dos partidos 
mayoritarios (PJ y UCR), los cuales han tenido desempeños electorales disímiles en la última década y media (Malamud y De Luca, 2016). El peronismo ha pasado a convertirse en una confederación de partidos provinciales (Leiras, 2007) en donde las coaliciones electorales nacionales dependen del apoyo o rechazo de dirigentes provinciales, generalmente gobernadores (Calvo y Escolar, 2005; Malamud y De Luca, 2016). Este bajo nivel de integración partidaria en el PJ ha llevado a que se presentaran varias coaliciones electorales para competir por la Presidencia, cada una de las cuales ha construido distintos acuerdos interpartidarios con dirigentes, gobernadores, legisladores y funcionarios (Leiras, 2007). La fortaleza o debilidad de esas coaliciones ha dependido, mayormente, de los alineamientos en el interior del partido.

La UCR, por su parte, ha tenido serias dificultades para construir una única coalición presidencial con posterioridad a la crisis del 2001 y la caída del Gobierno de la Alianza (Zelaznik, 2012 y 2013). Su espacio de supervivencia institucional han sido unos pocos Gobiernos provinciales que supo conservar (Malamud y De Luca, 2016; Leiras, 2007), al igual que un mínimo de bancas en la Cámara de Diputados y el Senado (Zelaznik, 2012), favorecido por la representación territorial del sistema electoral argentino (Calvo y Escolar, 2005). Sin embargo, ha sido escasa su suerte en aquellos intentos donde ha intentado desafiar a un PJ unificado en distintos distritos del país.

De modo que la desnacionalización partidaria no solo ha impactado en la dinámica competitiva de cada sistema provincial, sino que también ha producido efectos en los principales partidos nacionales. De acuerdo con la provincia que uno decida observar, encontrará distintas relaciones de fuerza entre el PJ y la UCR, al igual que distintos «tipos» de peronismo y radicalismo que dependen del nivel de cohesión y unidad partidaria que caracterice a cada caso. Nuevamente, esta disimilitud en el desempeño electoral y la vida interna de los dos partidos nacionales impacta en la construcción de coaliciones electorales en ambos niveles (nacional y subnacional) del sistema político.

En tercer lugar, las provincias «urbanas» han sido testigo de la aparición de nuevos partidos políticos ${ }^{10}$, generalmente asociados a liderazgos carismáticos que aprovecharon las ventajas de los medios masivos de comunicación y de electorados más «volátiles» (Calvo y Escolar, 2005; Leiras, 2007; Navarro y

10 Algunos ejemplos de ellos son Frente Grande/FREPASO (ya mencionado anteriormente), Acción por la República (APR, creado por el exministro de Economía Domingo Cavallo), Recrear para el Crecimiento (liderado por el exministro de Defensa, Ministro de Economía y dirigente radical, Ricardo López Murphy), Afirmación para Una República Igualitaria (ARI, creado por la también exdiputada radical Elisa Carrió) y Propuesta República (PRO, liderado por Mauricio Macri). 
Varetto, 2014). Estos nuevos partidos se han encontrado ante una disyuntiva en lo que a la construcción de su estructura se refiere. Frente a un calendario electoral exigente, con elecciones celebradas cada dos años, han encontrado serias dificultades para extender sus organizaciones partidarias desde los centros urbanos hacia el resto de los distritos del país. La estrategia privilegiada por estos nuevos partidos ha sido la de construir coaliciones electorales con los partidos mayoritarios y nacionales (PJ y UCR). El resultado de esas coaliciones, sin embargo, ha sido variable: mientras que la Alianza (Frente Grande/FREPASO, UCR y, posteriormente, APR) puede ser considerado un caso de fracaso (Leiras, 2007; Cruz, 2010), Cambiemos (PRO, UCR, CC-ARI y otros partidos distritales menores) pareciera haber aprendido en la buena dirección (Vommaro, 2017; Cruz, 2019).

Ahora bien, coincido con Escolar (2014b) en que, en un escenario de desnacionalización partidaria, no se puede sostener teóricamente que la construcción de identidades cívicas, la coordinación electoral y la integración del sistema político se da en los Estados federales multinivel de la misma manera que se da en los Estados unitarios. Adicionalmente, la teoría con la que actualmente desarrollamos investigaciones da por sentada la coordinación vertical y horizontal de las elites políticas (Escolar, 2014c). Si la FRD es un fenómeno que caracteriza a varios países latinoamericanos (Jones y Mainwaring; 2003; Freidenberg y Suárez Cao, 2014; Freidenberg, 2016a y 2016b; Morgenstern, 2017) entonces necesitamos supuestos teóricos que nos permitan comprender cómo, por qué y de qué manera las elites partidarias adoptan decisiones estratégicas a la hora de construir coaliciones electorales multinivel. Los dirigentes partidarios tienen incentivos para formar coaliciones, y la forma en que lo hacen incide sobre la integración vertical, la homogeneización horizontal y la extensión territorial de estos acuerdos.

Es en el marco de esta problemática donde conviene indagar teóricamente en los procesos de construcción de coaliciones electorales multinivel. El escenario generado por la evolución del sistema de partidos argentino ofrece una oportunidad para teorizar, conceptualizar y describir esos procesos de construcción política. Esto, a su vez, puede resultar de aplicación para otros casos con dinámicas, procesos e instituciones similares.

\section{APORTES TEÓRICOS PARA EL ESTUDIO DE LAS COALICIONES ELECTORALES MULTINIVEL}

Por coaliciones electorales multinivel me refiero a aquellas que están integradas por varios partidos que disponen de recursos electorales propios para acceder a cargos ejecutivos nacionales y subnacionales en un sistema de 
partidos multinivel. Estos acuerdos surgen como un mecanismo de coordinación política: son «procesos mediante los cuales [...] los políticos coordinan sus acciones electorales con el fin de ganar más escaños legislativos o carteras ejecutivas» (Cox, 2000: 49) ${ }^{11}$. Esta coordinación alcanza distintos grados de estabilidad dependiendo de las reglas internas definidas y acordadas por actores diferenciados que coinciden en objetivos concretos (Escolar, 2014a) ${ }^{12}$.

¿Por qué resulta necesario un abordaje multinivel de las coaliciones? La literatura especializada coincide en resaltar la insuficiencia de estudiar aisladamente los procesos políticos nacionales si queremos comprender cómo funcionan los sistemas políticos (Swenden y Maddens, 2009; Gibson y Suárez Cao, 2010; Došek y Freidenberg, 2013; Freidenberg y Suárez Cao, 2014). Esta salvedad no encuentra un freno en la distinción entre Estados unitarios o federales; es decir, ya sea por un proceso de descentralización (administrativa, fiscal y/o política) en el marco de un Estado unitario (Falleti, 2010), o bien por la existencia de un Estado federal cuyas unidades constitutivas tienen peso e importancia en la toma de decisiones públicas, podemos encontrar dinámicas políticas subnacionales en ambos tipos de Estado. Por ejemplo, podemos considerar que los niveles de competencia política subnacional serán más intensos y los cargos subnacionales en juego más atractivos para los actores partidarios mientras mayores sean las facultades, los recursos y las atribuciones de que dispone cada una de esas unidades políticas ${ }^{13}$.

Si el juego político no es unidimensional (Colomer y Martínez, 1995; Laver y Shepsle, 1996), entonces considero que el estudio las coaliciones no debe centrarse únicamente en un solo nivel (el nacional), sino que tienen que abarcarse los niveles inferiores (subnacional) y focalizarse especialmente en las relaciones que existan entre ellos. Esto convierte en relevantes a las unidades políticas subnacionales y a los procesos políticos que se den en su interior. Me

11 Traducción propia.

12 Escolar (2014a: 232) distingue de manera muy acertada la diferencia entre «integración política» $\mathrm{y}$ "coordinación política», asociando ambos conceptos a la química. Mientras que el primero se asemeja a la idea de «solución» (dos componentes se unen y forman uno nuevo), el segundo se relaciona con la «mezcla» (la unión de ambos no impide mantener las diferencias entre ellos). De esta forma, en una coalición los partidos políticos se mantienen como entidades propias.

13 En este sentido, la política subnacional adquiere relevancia y entidad propia: no porque en el nivel subnacional simplemente se refleja la competencia política nacional, sino porque las unidades subnacionales tienen características institucionales, políticas y electorales propias que las hacen atractivas y que generan sus propios incentivos y patrones de competencia. No son elecciones de «segundo orden» (Schakel y Jeffery, 2013). 
muevo así del «nacionalismo metodológico» imperante (Jeffery y Schakel, 2012). De esta forma, entiendo que un sistema político multinivel es aquel en el cual los partidos políticos compiten en distintos niveles y distritos en el territorio, los electores cuentan con varios votos para elegir entre distintos contendientes para distintos cargos públicos y mediados por diferentes tipos de reglas electorales (Došek y Freidenberg, 2013). Lo que caracteriza a estos sistemas políticos es la existencia de tantos niveles de competencia como niveles de autoridades electas existan. Me centraré principalmente en dos niveles de competencia electoral: existe un sistema de partidos a nivel nacional que emerge de elecciones nacionales, y tantos sistemas de partidos a nivel subnacional como unidades políticas conformen un Estado determinado (Calvo y Escolar, 2005; Swenden y Maddens, 2009; Leiras, 2007; Gibson y Suárez Cao, 2010).

Considero, así, que entre el nivel nacional y el nivel subnacional se pueden generar una multiplicidad de relaciones, vínculos e interacciones en tanto son dos arenas separadas, con lógicas y dinámicas propias, e incentivos específicos que operan sobre los actores políticos. Niveles que, sin embargo, se mantienen conectados entre sí e integran al sistema político en su conjunto. Esto quiere decir que en los sistemas políticos multinivel existe una lógica de competencia política "anidada»: las decisiones estratégicas que toman los actores partidarios se hacen a partir de analizar los incentivos que operan en cada nivel donde compiten (Tsebelis, 1990).

Ahora bien, ¿qué tipo de partidos políticos pueden formar coaliciones en un sistema político multinivel? Los hay de dos tipos. Por un lado, los partidos políticos nacionales, los cuales tienen presencia territorial a nivel nacional, se presentan en todos (o casi todos) los distritos electorales que integran un país y mantienen la misma etiqueta partidaria en ambos niveles ${ }^{14}$. Esto se desprende de lo discutido en el primer apartado de este artículo: la nacionalización de la competencia partidaria supone que los partidos políticos orientan su comportamiento en términos nacionales, dejando en un segundo plano la representación de intereses o clivajes locales (Jones y Mainwaring, 2003; Caramani, 2004; Chhiber y Kollman, 2004).

Así, en todo sistema político multinivel, un partido político nacionalizado implica que existe una organización partidaria en el nivel nacional (partido nacional) y tantas suborganizaciones locales o regionales como unidades

14 En una línea similar, la bibliografía europea ha consensuado una distinción entre dos tipos: partidos de ámbito estatal (PAE) y partidos de ámbito no estatal (PANE) (Pallarés y Keating, 2003). Los primeros serían los partidos nacionales y los segundos los partidos regionales o locales (subnacionales). 
subnacionales existan (partidos subnacionales). Entonces, si el juego político se desarrolla en varios niveles de un mismo sistema, entiendo también a los partidos de la misma manera, con la misma dinámica y bajo el mismo foco de análisis. Esto quiere decir que las elites partidarias nacionales tendrán sus propios objetivos, intereses y estrategias electorales en pos del mantenimiento de la estructura partidaria a nivel nacional y guiados por incentivos generados en esta arena de competencia. Por otro lado, las elites provinciales o regionales tendrán también sus propios objetivos, intereses y estrategias, pero enfocados en el nivel subnacional e influenciados por incentivos generados en este último (Wilson, 2009). De modo que mientras mayor sea la confluencia de objetivos políticos y estrategias partidarias entre elites nacionales y elites locales, mayor será la coordinación vertical de los partidos; mientras menor sea esa coincidencia, menor coordinación vertical tendrán (Thorlarkson, 2013).

Un segundo tipo de partido político son los provinciales o regionales: son todos aquellos que se concentran en determinadas regiones o zonas del país donde sí suelen hacerse fuertes en términos electorales, dado que no tienen mucho interés en ampliar su proporción de votos en el nivel nacional ni extender su presencia territorial a otros distritos del país. Estos partidos sí compiten por cargos a nivel nacional, pero en términos estratégicos privilegian la arena de competencia subnacional sobre la competencia nacional y buscan consolidarse desde ese lugar como actores partidarios de relevancia. Respecto a esto, tomo en cuenta la distinción que realiza Stefuriuc (2009) entre dos tipos de partidos regionales: a) aquellos que tienen capacidad para gobernar únicamente en el distrito donde nacieron y se extendieron como organizaciones (ya sea por decisión propia o por tener poco peso en la competencia nacional), y b) aquellos que pueden jugar un juego de dos niveles (nacional y subnacional) porque el sistema electoral nacional se los permite. Brancati (2008: 138) coincide con este planteamiento al definir a los partidos regionales como aquellos que «compiten y ganan votos en una sola región del país. [...] pueden participar en elecciones nacionales o regionales siempre y cuando solo compitan en una región del país en cualquier nivel [de competencia]» ${ }^{15}$.

15 Traducción propia. Brancati (2008) agrega que los partidos regionales no necesariamente son partidos étnicos ni religiosos. Este punto refuerza nuestra noción de partido regional o local que solamente compiten en determinadas zonas del país. $\mathrm{Al}$ respecto, Lublin (2014) también destaca que la aparición de este tipo de partidos no necesariamente está asociado al conflicto político o a la falta de representación, sino que es producto directo de las reglas electorales. Este factor incide directamente en la aparición, consolidación y ¿éxito? de los partidos regionales. 
El rol que cumplen los partidos regionales no es menor si tenemos en cuenta la importancia y el papel que desempeña el nivel subnacional en la dinámica política. Brancati resalta que «la descentralización política alienta a los políticos a formar partidos regionales, y a los votantes a votar por ellos, dado que los sistemas de gobierno descentralizados tienen legislaturas regionales en las cuales [estos partidos] tienen una gran oportunidad para gobernar en caso de que no puedan hacerlo a nivel nacional» $(2008: 136)^{16}$.

Entonces, ¿qué tipos de acuerdos electorales se pueden formar entre distintos tipos de partidos políticos? El gráfico 4 plantea un esquema hipotético de "coaliciones cruzadas» como una respuesta estratégica de los actores partidarios en esquemas de competencia partidaria con un alto grado de «territorialización» o desnacionalización ${ }^{17}$.

Gráfico 4. Coaliciones electorales y tipos de partido politico según niveles de competencia partidaria en un sistema multinivel

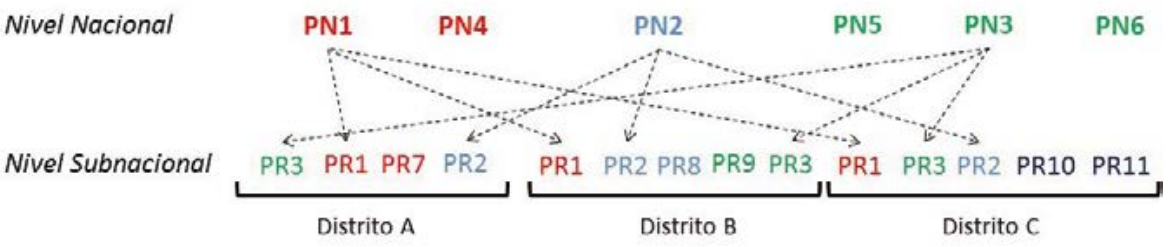

Fuente: elaboración propia. Las flechas puntuadas indican las suborganizaciones locales de los partidos nacionales y los colores indican las coaliciones electorales «cruzadas» construidas.

En este hipotético escenario de competencia multinivel se observan distintas configuraciones de coaliciones electorales nacionales y subnacionales. Se identifican seis partidos nacionales (PN1, PN2, PN3, PN4, PN5 y PN6), algunos con sus suborganizaciones locales (PN1=PR1, PN2=PR2 y PN3=PR3) y otros seis partidos regionales (PR4, PR5, PR6, PR7, PR8 y PR9). Los colores indican las distintas coaliciones conformadas en cada uno de los niveles (por ejemplo, en el nivel nacional PN1 + PN4 y PN3 + PN5 + PN6) y las

16 Traducción propia.

17 Es muy interesante el estudio que coordinaron Reynoso y Espinosa Santiago (2017) sobre las alianzas «contra natura» en México, caso que muestra algunas similitudes con el argentino. El capítulo de Reynoso y Miño (2017) indica como condiciones relevantes para la construcción de coaliciones de este tipo la percepción del aumento de la competitividad electoral, la fractura del actor hegemónico y la desconexión de los niveles de competencia a partir del desdoblamiento del calendario electoral. 
conformadas en cada uno de los distritos (por ejemplo, PR1 + PR7 en Distrito A).

Ahora bien, en sistemas partidarios con FRD podemos esperar que si los partidos políticos deciden competir por la mayor cantidad de cargos en juego (nacionales y provinciales) deban recurrir a las coaliciones como una estrategia para aumentar su caudal electoral para cumplir distintos objetivos políticos: obtener una mayor cantidad de cargos públicos (legislativos y ejecutivos), superar el mínimo de votos exigido por ley para ingresar en el reparto de esos cargos, adquirir más financiamiento público, mantener su personería jurídica, etc. Además de ello, el aumento de la fragmentación partidaria que mencioné en apartados anteriores puede darse debido a la presencia cada vez más recurrente de partidos políticos que deciden competir por cargos locales o provinciales únicamente (Clerici, 2015) o bien al desmembramiento de dos partidos nacionales con fuerte presencia en cada nivel de competencia (Calvo y Escolar, 2005; Leiras, 2007). En estos escenarios adquieren una relevancia importante las suborganizaciones locales de los partidos nacionales y los partidos locales o provinciales. En otras palabras, el nivel subnacional se vuelve atractivo para las elites partidarias.

De esta forma, en un escenario donde la fragmentación partidaria aumenta, pero lo hace de manera desproporcionada en cada uno de los distritos, la salida estratégica que tienen todo partido político que decide competir por la mayor cantidad de cargos en juegos, en múltiples niveles de competencia y en la mayor cantidad de distritos posibles, es la construcción de una coalición electoral multinivel. Estos acuerdos entre partidos políticos tienen dos dimensiones (o niveles). Un nivel nacional en el cual la coalición busca competir por cargos nacionales; específicamente, por la Presidencia de la Nación y legisladores nacionales. Este nivel lo integran partidos nacionales. Un segundo nivel es el subnacional, en el cual la coalición se construye para competir por cargos provinciales: gobernador y legisladores provinciales. En este nivel, la coalición está integrada por suborganizaciones locales de partidos nacionales y/o por partidos provinciales.

Estos acuerdos de coordinación política implican una conjunción de intereses y objetivos de una multiplicidad de dirigentes de distintos partidos políticos, locales, provinciales y nacionales, pero que no siempre tienen una estructura piramidal en la jerarquía de poder (Leiras, 2007). Quienes integran la coalición a nivel nacional generalmente son quienes impulsan una candidatura presidencial que es la que «arrastra los votos», tiene inserción en cierta parte del electorado y un conocimiento público extendido en algunas regiones del país (si no en todas o en su mayoría). Por otro lado, quienes integran la coalición en cada provincia son los que controlan los recursos electorales, financieros y humanos para movilizar al electorado, instalar a los candidatos y 
posicionar a la coalición como un actor del tablero. El grado de autonomía que tengan estos actores que «tienen control sobre el territorio» dependerá del modelo de construcción de la coalición y de la relación de fuerzas entre los socios del acuerdo. Independientemente de estas diferencias, el éxito en la consecución de los objetivos políticos que fijen las elites partidarias dependerá de la conjunción de cada nivel dirigencial: tanto el candidato presidencial como su entorno necesitan de los recursos político-partidarios del territorio que les proporcionan los dirigentes provinciales, mientras que estos necesitan de una figura nacional que resulte atractiva para el electorado distrital al que intentan llegar. Hay una cooperación mutuamente interdependiente entre ambos niveles (Leiras, 2007).

Entonces, ¿`ómo se produce este proceso de construcción de la coalición electoral multinivel a la que estoy haciendo referencia? De modo similar a cómo se construyen las organizaciones partidarias para Panebianco (1990), puedo identificar dos modelos bien distintos, pero que no necesariamente tienen que ser contradictorios.

Las coaliciones electorales pueden construirse por penetración territorial. En estos casos, la construcción de la coalición se realiza desde un centro político que controla, estimula y desarrolla su crecimiento y extensión hacia la periferia. Generalmente, ese "centro político» está asociado geográficamente a un determinado «bastión electoral» (Escolar, 2001) ${ }^{18}$ desde el cual se buscar dar el «salto» de la coalición hacia otras provincias o regiones para aumentar el caudal electoral y posicionar a los candidatos de la coalición en el electorado. Por ejemplo, un partido A nace en una ciudad urbana con una gran concentración del electorado y decide construir su coalición desde ese territorio hacia los demás distritos del país. Este proceso de conformación de la coalición tiene un fuerte componente temporal: el «centro político» define los plazos, las etapas y los tiempos en los cuales se procede para extenderla en el resto de los distritos. Desde esta perspectiva, la construcción de la coalición se percibe como un proceso de extensión territorial con el cual se busca instalar en el electorado a los candidatos (nacionales y provinciales), el programa de gobierno, el nombre y los símbolos del acuerdo, sus líderes, los partidos que lo integran, etc. Adicionalmente, este crecimiento territorial se realiza sobre una estructura política que no siempre está presente en la mayor parte de los distritos.

18 Un «bastión electoral» es un determinado distrito donde los resultados electorales «se corresponden con opciones políticas partidarias duraderas expresadas en la preferencia sistemática de los electores respecto a la oferta electoral de una fuerza política determinada» (Escolar, 2001: 159). De esta forma, quien gana sostenidamente lo hace gracias al «voto cautivo» (ibid.: 194). 
En este proceso de construcción la relación entre el «centro político» y los dirigentes de otros distritos es en gran medida asimétrica: es el primero el que tiene capacidad y autonomía decisora para definir candidaturas, (la mayoría de) los miembros de la coalición y el programa de gobierno, por ejemplo. A medida que la coalición se va extendiendo hacia otros distritos, quienes son los responsables provinciales de conformarla siguen las directrices generales establecidas en el centro. Esto no implica que los acuerdos partidarios que se conformen en otras provincias tengan nula capacidad decisora, sino que las cuestiones más relevantes que definen los plazos, las pautas y las reglas de construcción de la coalición multinivel son fijadas mayormente por el "centro político».

Un modelo alternativo de construcción de la coalición es el de difusión territorial. A diferencia del anterior, en estos casos la conformación del acuerdo se da por "generación espontánea» (Panebianco, 1990: 110) entre los distintos partidos políticos que lo conforman. El modelo de construcción se lleva a cabo sobre una estructura política que ya se encuentra extendida en el territorio nacional. Las elites nacionales y provinciales acuerdan un nombre y un logo para la coalición, definen las candidaturas a distintos cargos en juego, establecen las reglas de convivencia, etc. Este proceso se lleva a cabo en una gran cantidad de distritos posibles de manera simultánea. Estas elites con asiento en las provincias deciden darle forma al acuerdo nacional, el cual se integra con acuerdos locales. Por ejemplo, un partido A decide conformar una coalición electoral con el partido B y el partido C; estos acuerdos se van replicando automáticamente en el resto de las provincias y los niveles del sistema político.

En este tipo de construcciones también hay un fuerte componente territorial (la coalición electoral busca abarcar la mayor cantidad de territorio posible) pero, a diferencia de la penetración territorial, en el modelo de difusión no hay un alto grado de control de parte de un «centro». Los partidos que conforman la coalición en cada distrito tienen un mayor grado de autonomía y capacidad decisora para definir cuestiones relevantes, como pueden ser las candidaturas en el distrito, la adaptación de la plataforma de gobierno al distrito específico, etc. Más importante aún, hay un bajo control por parte de un distrito específico sobre los plazos, las reglas y las etapas de esa construcción. Existen ciertas directrices generales establecidas que deben ser respetados por todos los distritos, pero se deja un mayor margen de acción a cada uno. El «bastión electoral» no es uno solo, sino que son varios los distritos desde los cuales se construye la coalición electoral multinivel. De esta forma, la relación entre las elites partidarias que integran la coalición es más simétrica: hay cierto balance y equilibrio entre todos los distritos en los cuales se conforma el acuerdo.

La siguiente tabla sintetiza las principales diferencias entre ambos modelos de construcción. 


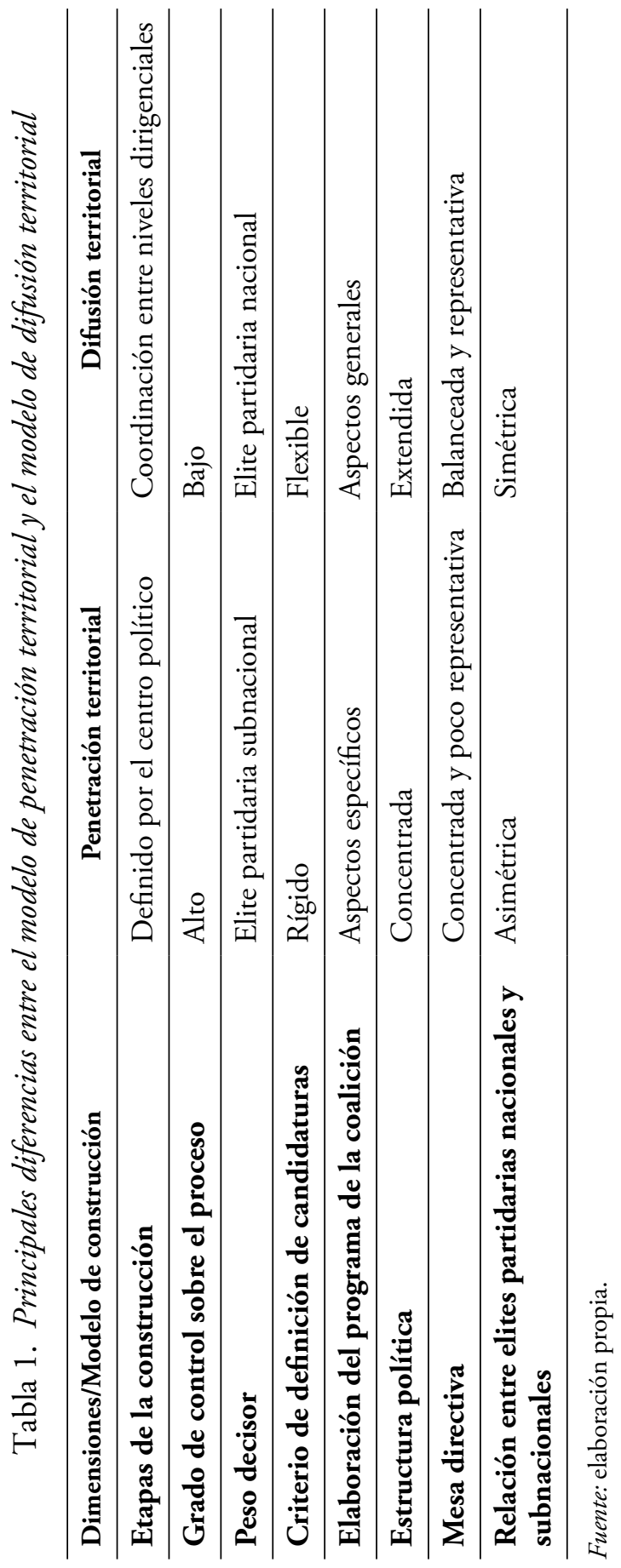


El gráfico 5 esquematiza visualmente los dos modelos de construcción de una coalición electoral multinivel. Como puede apreciarse, en un esquema de penetración territorial un centro político controla el proceso, no solo seleccionando los distritos en los cuales compite la coalición, sino también definiendo los socios del acuerdo, los cuales, a su vez, pueden variar en cada provincia. En un esquema de difusión territorial, en cambio, la construcción de la coalición se lleva a cabo con escaso peso de un centro que coordina y define la política de acuerdos, por lo que se genera de manera espontánea en cada distrito. Hay un menor control sobre la selección de los distritos y sobre los aliados que integran el acuerdo ${ }^{19}$.

\section{Gráfico 5. Construcción de coaliciones electorales multinivel por penetración y por difusión territorial}
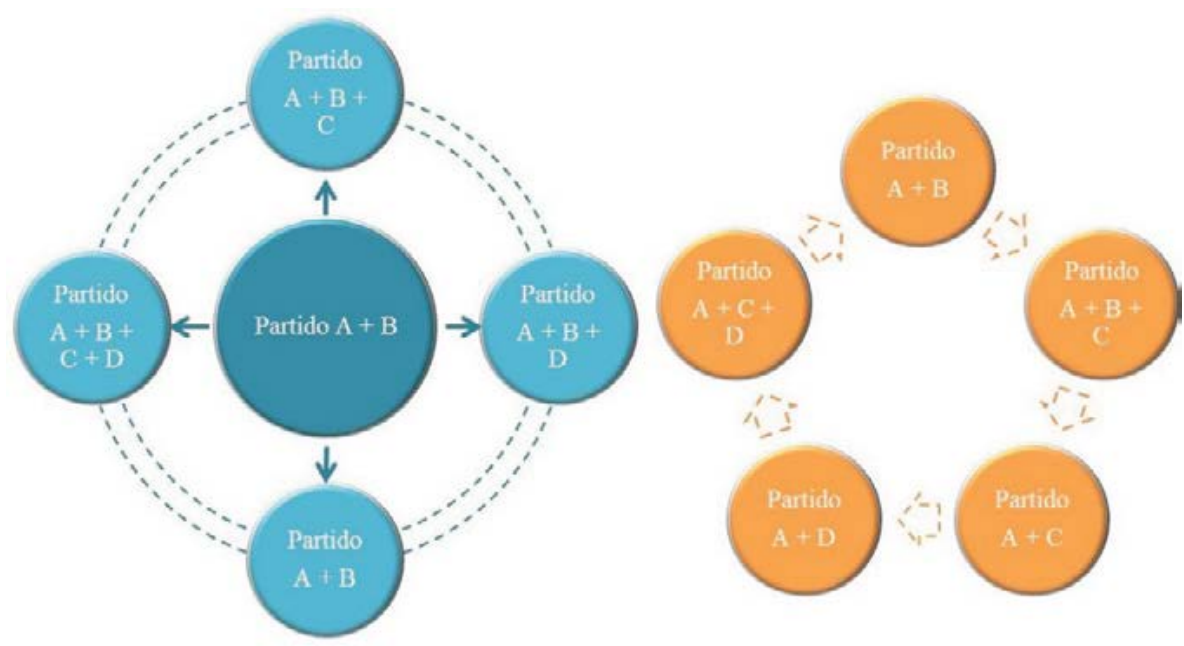

Fuente: elaboración propia.

Ahora bien, aunque la construcción de coaliciones electorales multinivel se sustenta en incentivos electorales e institucionales, ello no impide que

19 Estas coaliciones pueden llegar a tener un bajo grado de congruencia (Stefuriuc, 2009). Esto se ve potenciado por la misma dinámica del sistema partidario: mientras mayor sea la diferencia entre los sistemas partidarios provinciales, y entre estos y el sistema partidario nacional, entonces más diferentes deberían ser las coaliciones electorales multinivel en sus partes componentes. 
surjan algunas complicaciones en el proceso. En el próximo apartado precisaré ambas cuestiones.

\section{INCENTIVOS Y PROBLEMAS PARA EL PROCESO DE CONSTRUCCIÓN COALICIONAL}

Tal como se desprende del marco teórico anterior, las elites nacionales y subnacionales disponen de la capacidad de decisión necesaria para construir coaliciones electorales multinivel: es la salida estratégica óptima en un escenario de FRD. Dado que las coaliciones son una forma específica de coordinación política, para lograr esos acuerdos las elites realizan un cálculo estratégico basado en tres premisas fundamentales (Cox, 2004): a) la distribución de preferencias del electorado; b) una noción más o menos cercana sobre su propio peso electoral, y c) ciertas expectativas sobre cómo puede ser el resultado de la elección general. Ahora bien, si parto del supuesto de que un proceso de desnacionalización partidaria como el argentino derivó en la pérdida de peso de las etiquetas partidarias nacionales (Calvo y Escolar, 2005) y en el consecuente aumento de la importancia de las suborganizaciones partidarias provinciales (Leiras, 2007), entonces debo presuponer que todo proceso de negociación de una coalición electoral se realiza desde una perspectiva distrital geográficamente concentrada. Consecuentemente, se pueden producir «problemas de coordinación electoral» entre distritos. Esto es, los dirigentes partidarios provinciales no siempre están de acuerdo entre sí sobre la estrategia electoral que seguir, los socios que pueden formar parte de un acuerdo o, incluso, quién debe ser el candidato presidencial de una coalición. Estas tensiones también suelen generarse en el vínculo con los dirigentes partidarios nacionales.

Adicionalmente, si la garantía de estabilidad radica en la supervivencia provincial, ¿por qué intentar dar el «salto multinivel»? ¿Por qué invertir en una coalición electoral, teniendo en cuenta los costos, el tiempo y los recursos necesarios para hacerlo? En esta dirección, Cox (2004) entiende que las elites pueden coordinar sus decisiones por cinco razones; me centraré en dos relevantes para este trabajo.

El primer incentivo se centra en la lógica propia de la competencia presidencial. Tal como indica Leiras (2007), la competencia por el máximo cargo del sistema político puede generar incentivos para que suborganizaciones provinciales conformen acuerdos amplios para alcanzarlo. En ese proceso de intercambio, el territorio, la campaña y los votos lo aportan los dirigentes provinciales; mientras que la imagen, el carisma y el candidato lo ofrecen las estructuras nacionales del acuerdo electoral. Dado que los cargos legislativos se distribuyen entre los distintos distritos, los partidos políticos tienen incentivos para alcanzar la mayor 
cantidad posible de bancas en el Congreso ya sea para dotar de una mayoría sólida a su candidato presidencial (en caso de ganar la elección) o controlar y limitar el poder del Gobierno de turno (en caso de perderla). De esta forma, la construcción de una coalición electoral multinivel que se extienda en gran parte del territorio permite a sus integrantes acudir a mayores fuentes de financiamiento, ya sea en modalidad pública, privada o mixta. Tal como reconoce Leiras (2007: 47-57), los recursos financieros son claves para el sostenimiento de las estructuras partidarias, especialmente para la estabilidad de las coaliciones y, más aún, en el contexto de competencia electoral en las democracias contemporáneas (Mair y Katz, 2015).

Cox (2004) también identifica otro incentivo en la consolidación de los partidos nacionales (denominados "grupos focales»): la posibilidad de resolver los problemas de coordinación electoral entre distritos. Es decir, la existencia de partidos nacionales permite a las elites políticas decidir dónde competir, cuántos, cómo y bajo qué etiquetas. "Las elites hacen uso de grupos políticos focales o partidos [...] que buscan coordinar simultáneamente su entrada en diversos escenarios multidistritales con el propósito de obtener mayorías legislativas consistentes o promover una candidatura superior (como, por ejemplo, la presidencial)» (Escolar, 2014b: 55). Sin embargo, tal como indiqué anteriormente, ¿qué ocurre cuando los partidos políticos nacionales tienen distinto peso territorial en distintas provincias o existen partidos provinciales que concentran gran parte del electorado y compiten de igual a igual contra los partidos nacionales? Nuevamente, la respuesta radica en recurrir a la construcción de coaliciones electorales multinivel, donde distintos partidos políticos aportan al acuerdo recursos organizacionales, humanos y de campaña, supliendo las carencias de sus socios y en pos de alcanzar objetivos comunes.

Con ambos puntos coinciden Colomer y Martínez (1995) al plantear que, en sistemas parlamentarios de múltiples niveles, las elites partidarias pueden aceptar ingresar en coaliciones sobredimensionadas en algunos distritos a cambio de formar coaliciones mayoritarias en otros. De esta manera, la coordinación entre niveles y arenas importa en pos de alcanzar determinados objetivos estratégicos propios y específicos de cada actor en cada unidad subnacional.

Por último, existe dos complicaciones no menores en la coordinación multinivel de las elites partidarias y que representan justificaciones relevantes para estudiar este fenómeno desde la perspectiva que ofrece este trabajo. Este tipo de acuerdo o coordinación entre aliados partidarios supone una serie de condiciones de negociación que tienen que estar dadas para que la coalición pueda tener opciones efectivas de lograr los objetivos acordados (Carroll 2007). Primero: que los partidos políticos acuerden previamente los distritos en donde cada uno se concentrará y con qué criterios lo definirán: si es por 
tradición histórica, por no querer perder el distrito, por interés en los beneficios político-institucionales que le reportarán a cada partido, por inserción en el electorado, etc. Segundo: una vez alcanzado ese acuerdo, los partidos miembros de la coalición no deben interferir en los distritos de sus socios si ya consensuaron el «reparto de funciones», ya que la tentación por aumentar el caudal electoral propio siempre se encuentra a la vuelta de la esquina.

Adicionalmente, tal como indica Cox (2004), la literatura clásica sobre sistema de partidos presupone que los resultados electorales que se dan a nivel del distrito (provincial, por ejemplo) se trasladan automáticamente al nivel nacional. Es decir, los electores eligen candidatos en su provincia, los votos se suman entre todos los distritos y el comportamiento electoral que se genera en el nivel subnacional se reproduce automáticamente a nivel nacional. Sin embargo, en varios casos de estudio ese traslado no es automático ni inmediato. En la misma dirección, no se puede pensar que los acuerdos electorales entre partidos que se dan en el nivel provincial se trasladan automáticamente al nivel nacional. No solo porque esos acuerdos pueden tener un bajo grado de congruencia (Clerici, 2015), sino también porque esa decisión de dar el «salto multinivel» depende de los cálculos electorales que realicen los dirigentes partidarios, tanto los nacionales como los provinciales. Pueden, por ejemplo, privilegiar competir en el nivel local o restar apoyo político a sus candidatos nacionales. La elección de competir depende de la coyuntura electoral del momento, del esquema de acuerdos internos que gobiernan la coalición, de las reglas de funcionamiento acordadas entre los socios del acuerdo y de los incentivos producidos por el sistema electoral (por ejemplo, el calendario electoral pautado). Las elites partidarias tienen un menú de opciones que ofrecen los marcos legales y desde allí privilegian determinados modelos de construcción para sus coaliciones.

\section{CONCLUSIONES}

Este trabajo se ha centrado en proponer un modelo teórico para estudiar las decisiones estratégicas de las elites partidarias a la hora de construir coaliciones electorales en sistemas partidarios multinivel. Son procesos políticos que pueden ser entendidos como un castillo de naipes (house of cards): quienes tienen el control de las cartas (los partidos políticos) van uniendo unas con otras hasta formar una pirámide (coalición) que tiene como objetivo lograr cargos públicos en juego (electoral) y para ello se forma en varias arenas de competencia (multinivel).

Apilar las cartas, conectarlas y armar pisos sólidos para los niveles superiores tiene sus dificultades. Los castillos de naipes no siempre resultan 
sencillos de construir. Es más, me atrevería a decir que son más los casos que tienen dificultades y no siempre logran altos grados de acuerdo multinivel, que aquellos que encuentran el camino causal para alcanzarlo. Así es como creo que tiene que pensarse, teorizarse y analizarse la discusión en torno a las coaliciones políticas.

Esta es la fórmula indicada para escenarios de competencia electoral donde la desnacionalización es una tendencia marcada, recurrente y, a veces, sostenida. Los países que presentan distintos patrones de comportamiento electoral en cada una de las subunidades políticas que los integran, o bien que tienen distintos actores políticos en cada una de ellas, plantean un desafío a las elites partidarias. El desafío es lograr acuerdos amplios y que adquieran una dinámica de formación multinivel. Es la mejor opción que un marco legal determinado les puede permitir para competir por la mayor cantidad de cargos públicos en juego. No por eso resulta casual que durante los ańos que más se potenció la desnacionalización partidaria en, por ejemplo, Argentina (2003-2011), sea el momento en el cual más coaliciones electorales multinivel hubo en el país (Clerici, 2015; Cruz, 2019). Esto se aplica tanto para la competencia presidencial, como la legislativa nacional y la de gobernadores provinciales. En este punto específico resulta útil una reflexión repetida por un reconocido dirigente político: «Salvo en la elección de 1983, después todas fueron coaliciones. Y esa tendencia se mantendrá» (Cruz, 2019). También lo hará en la mayor parte de los países latinoamericanos.

En este artículo me he propuesto desarrollar algunas ideas propias sobre cómo creo que se arman las coaliciones: quiénes las hacen, cómo se acercan, por qué, con qué herramientas cuentan, qué les permite hacer el marco legal donde deciden intervenir, qué no les permite. En particular, cómo llevan a cabo el proceso de construcción coalicional. Ahí creo que pueden existir dos modelos diferenciados, pero que por momentos pueden cruzar elementos comunes. Por un lado, las coaliciones que se forman por penetración territorial cuentan con uno (o un conjunto limitado) de bastiones electorales (Escolar, 2001) desde los cuales los dirigentes partidarios que «arman» controlan prácticamente todo: quiénes son los aliados, quiénes los candidatos, qué nombre usarán, cómo se repartirán los recursos, qué reglas guiarán el proceso, cómo se repartirán los lugares. En definitiva, dan forma al acuerdo y controlan las áreas de incertidumbre de la coalición (Panebianco, 1990). En contraposición a este modelo existe el de difusión territorial. En estos casos, los partidos se unen en un acuerdo multinivel, pero sin la presencia de un centro territorial que dirija el acercamiento. Existe un grupo de dirigentes que representan de manera más balanceada la mesa de decisiones y, al mismo tiempo, cuentan con una estructura partidaria que está más extendida en el territorio. Estos dirigentes pueden pautar algunas reglas generales de construcción coalicional, 
pero queda en las elites partidarias provinciales la decisión de respetarlas, cambiarlas o doblarlas un poco en pos de su propio beneficio.

Por último, considero que las coaliciones constituyen un fenómeno relevante de la política partidaria y electoral y que, muy probablemente, llegaron para quedarse en la competencia política regional. Las pirámides de cartas son una realidad, que de manera poco probable cambie en el futuro inmediato. El trabajo también revela que esta agenda de investigación no está cerrada, todo lo contrario. Hace falta presentarla. Hace falta debatirla. Hace falta ampliarla. Y, por último, es necesario que sigamos estudiando este tipo de acuerdos entre partidos políticos. La evolución de los sistemas partidarios nos obliga a hacerlo. Nada es sencillo, nada es simple.

\section{Bibliografía}

Abal Medina, J. M. y Suárez Cao, J. (2002). La competencia partidaria en la Argentina: sus implicancias sobre el régimen democrático. En M. Cavarozzi y J. M. Abal Medina (comps.). El asedio a la politica. Los partidos latinoamericanos en la era neoliberal (pp. 423433). Rosario: Homo Sapiens.

Albala, A. (2016). Presidencialismo y coaliciones de gobierno en América Latina: un análisis del papel de las instituciones. Revista de Ciencia Política, 36 (2), 459-479. Disponible en: https://doi.org/10.4067/S0718-090X2016000200003.

— (2017). Bicameralism and Coalition Cabinets in Presidential Polities: A configurational analysis of the coalition formation and duration processes. The British Journal of Politics and International Relations, 19 (4), 735-754. Disponible en: https://doi. org/10.1177/1369148117727440.

Altman, D. (2000). The politics of coalition formation and surivival in multi-party presidential democracies. The case of Uruguay, 1989-1999. Party Politics, 6 (3), 259-283. Disponible en: https://doi.org/10.1177/1354068800006003001.

Amorim Neto, O. (2006). Presidencialismo e Governabilidade nas Américas. Rio de Janeiro: Editora FGV; Konrad Adenauer Stiftung.

Braga, M. do S. (2006). Dinâmica de coordenação eleitoral em regime presidencialista e federativo: determinantes e conseqüências das coligaçôes partidárias no Brasil. En G. A. Dillon Soares y L. R. Renno (eds.). Reforma política: Liçäes da histäria recenté. Río de Janeiro: Fundaçấo Getúlio Vargas.

Brancati, D. (2008). The Origins and Strenghts of Regional Parties. British Journal of Political Science, 38 (1), 135-159. Disponible en: https://doi.org/10.1017/S0007123408000070.

Calvo, E. y Escolar, M. (2005). La nueva política de partidos en la Argentina. Crisis politica, realineamiento partidarios y reforma electoral. Buenos Aires: Prometeo; Proyecto Educación y Nuevas Tecnologías.

Caramani, D. (2004). The Nationalisation of Politics. The Formation of National Electorates and Party Systems in Western Europe. Cambridge: Cambridge University Press. Disponible en: https://doi.org/10.1017/CBO9780511616662. 
Carroll, R. A. (2007). The Electoral Origins of Governing Coalitions [tesis doctoral]. San Diego: University of California. Disponible en: https://bit.ly/2UmPbMS.

Chasquetti, D. (2008) Democracia, presidencialismo y partidos politicos en América Latina: Evaluando la «dificil combinación». Montevideo: Ediciones CAUCE; Facultad de Ciencias Sociales, Universidad de la República de Uruguay; Comisión Sectorial de Investigación Científica.

Cheibub, J. A., Przeworski, A. y Saiegh, S. M. (2004). Government Coalitions and Legislative Success Under Presidentialism and Parlamentarism. British Journal of Political Science, 34, 565-587. Disponible en: https://doi.org/10.1017/S0007123404000195.

Chhibber, P. y Kollman, K. (2004). The Formation of National Party Systems: Federalism and Party Competition in Canada, Great Britain, India, and the United States. Princeton: Princeton University Press.

Clerici, P. (2015). La creciente importancia de las alianzas electorales en un escenario de competencia territorializada. El caso argentino. Revista SAAP: Sociedad Argentina de Análisis Politico, 9 (2), 313-341.

- (2016). Juegos de congruencia: las estrategias de alianzas electorales de la UCR y el PJ en Argentina (1983-2013). Revista Uruguaya de Ciencia Política, 25 (2), 15-33.

- (2017). Cada quien atiende su juego. Un estudio de las alianzas electorales en la pelea por la Cámara Baja en Argentina (1983-2013). Desarrollo Económico, 56 (220), 393-415.

- (2018). La influencia de la dicotomía oficialismo/oposición sobre la congruencia de las coaliciones electorales en Argentina. Revista POSTData, 23 (1), 121-149.

— , Albala, A. y Reniú, J. M. (2018). Conclusion. En A. Albala y J. M. Reniú (eds.). Coalition Politics and Federalism. Cham: Springer. Disponible en: https://doi. org/10.1007/978-3-319-75100-9.

Clerici, P., Cruz, F., Goyburu, L., Skigin, N., Seira, I., Albala, A. y Molina, A. (2016). Coaliciones políticas en América Latina. Revista Iberoamericana, 16 (61), 237-266.

Clerici, P. y Scherlis, G. (2014). La Regulación de Alianzas Electorales y sus Consecuencias en Sistemas Multi-nivel en América Latina. Revista del Instituto de Investigaciones Jurídicas y Sociales Ambrosio L. Gioja, 8 (12), 79-98.

Colomer, J. y Martínez, F. (1995). The paradox of coalition trading. Journal of Theoretical Politics, 7 (1), 41-63. Disponible en: https://doi.org/10.1177/0951692895007001003.

Cox, G. W. (2000). Electoral coordination. En R. Rose (ed.). International Encyclopedia of Elections. Londres: MacMillan.

- (2004). La coordinación estratégica de los sistemas electorales del mundo. Hacer que los votos cuenten. Barcelona: Gedisa Editorial.

Cruz, F. (2010). Relaciones e interacciones partidarias en coaliciones de gobierno. Los casos de la Alianza, la Concertación y el Frente Amplio. Revista Debates Latinoamericanos 8 (15), 1-26.

- (2014). ¿ ¿Socios de menor nivel? Aportes para el estudio de las coaliciones subnacionales en sistemas políticos multinivel. Revista Uruguaya de Ciencia Política, 23 (1), 11-39.

- (2019). Socios pero no tanto. Partidos y coaliciones en Argentina, 2003-2015. Buenos Aires: Editorial Universitaria de Buenos Aires.

— y Clerici, P. (2015). Cuando el problema es definir (en el área). Retomando el debate sobre coaliciones políticas en América Latina. En XII Congreso Nacional de Ciencia Politica. Sociedad Argentina de Análisis Político (SAAP) (Mendoza, 12-15 de agosto de 2015). 
De Riz, L. y Adrogué, G. (1991). Democracia y elecciones en la Argentina: 1983-1989. En D. Nohlen y L. de Riz (coords.). Reforma institucional y cambio politico en Argentina. Buenos Aires: Centro de Estudios de Estado y Sociedad; Legasa.

Deheza, G. I. (1998). Gobiernos de coalición en el sistema presidencial: América del Sur. En D. Nohlen y M. Fernández (eds.). El presidencialismo renovado. Instituciones y cambio político en América Latina (pp. 151-169). Caracas: Ediciones Nueva Sociedad.

Devoto, L. M. y Olmeda, J. C. (2017). Juntos pero revueltos. Estrategias electorales y coaliciones partidarias para la elección de diputados locales en los estados mexicanos (20002016). Revista Colombia Internacional, 90, 157-187. Disponible en: https://doi. org/10.7440/colombiaint90.2017.06.

Došek, T. y Freidenberg, F. (2013). La congruencia de los partidos y los sistemas de partidos multinivel en América Latina: conceptualización y evaluación de algunas herramientas de medición. Politai: Revista de Ciencia Política, 4 (7), 161-178.

Escolar, M. (2001). La posibilidad de gerrymandering politico. Estabilidad y concentración geográfica del voto partidario. En E. Calvo y J. M. Abal Medina (eds.). El federalismo electoral argentino: sobrerrepresentación, reforma politica y gobierno dividido en la Argentina (pp. 175-196). Buenos Aires: Editorial Universitaria de Buenos Aires.

(2014a). Juntos pero no revueltos. Segmentación estratégica y coaliciones efímeras. En M. Escolar y J. M. Abal Medina (coords.). Modus Vivendi. Política Multinivel y Estado Federal en Argentina (pp. 217-254). Buenos Aires: Prometeo.

— (2014b). Nacionalización, comunidad cívica y coordinación electoral. Problemas para la integración del sistema político en Estados democráticos multinivel. En M. Escolar y J. M. Abal Medina (coords.). Modus Vivendi. Politica Multinivel y Estado Federal en Argentina (pp. 29-78). Buenos Aires: Prometeo.

- (2014c). Introducción: La integración del sistema político como presupuesto o problema teórico. En M. Escolar y J. M. Abal Medina (coords.). Modus Vivendi. Política Multinivel y Estado Federal en Argentina (pp. 11-28). Buenos Aires: Prometeo.

Falleti, T. G. (2010). Descentralization and Subnational Politics in Latin America. Cambridge: Cambridge University Press. Disponible en: https://doi.org/10.1017/CBO9780511777813.

Flisfisch, A. (1990). Parlamentarismo, presidencialismo y coaliciones gobernantes. Documento de Trabajo, 459. FLACSO-Chile.

Freidenberg, F. (ed.) (2016a). Los sistemas de partidos de América Latina (1978-2015): México, América Central y República Dominicana (vol. 1). México D. F.: Universidad Nacional Autónoma de México; Instituto Nacional Electoral.

— (ed.) (2016b). Los sistemas de partidos de América Latina (1978-2015). Cono Sur y Países Andinos (vol. 2). México D. F.: Universidad Nacional Autónoma de México; Instituto Nacional Electoral.

— y Suárez Cao, J. (eds.) (2014). Territorio y poder: nuevos actores y competencia politica en los sistemas de partidos multinivel en América Latina. Salamanca: Ediciones Universidad de Salamanca.

Gerring, J. (2010). Case selection for case-study analysis: qualitative and quantitative techniques. En J. M. Box-Steffensmeier, H. E. Brady y D. Collier (eds.). The Oxford Handbook of Political Methodology (pp. 645-684). Oxford: Oxford University Press. 
Gibson, E. y Suárez Cao, J. (2010). Federalized Party Systems and Subnational Party Competition: Theory and an Empirical Application to Argentina. Comparative Politicos, 43 (1), 21-39. Disponible en: https://doi.org/10.5129/001041510X12911363510312.

Jeffery, C. y Schakel, A. (2012). Insights: Methods and Data Beyond Methodological Nationalism. Regional Studies, 47 (3), 1-3.

Jones, M. P. y Mainwaring, S. (2003). The Nationalization of Parties and Party Systems. An Empirical Measure and an Application to the Americas. Party Politics, 9 (2), 139-166. Disponible en: https://doi.org/10.1177/13540688030092002.

Kinzo, M. D. (2003). Parties and Elections: Brazil's Democratic Experience Since 1985. En M. D. Kinzo y J. Dunkerley (eds.). Brazil Since 1985: Economy, Polity, and Society (pp. 42-62). London: Institute of Latin American Studies; University of London.

Krause, S., Dantas, H. y Miguel, L. F. (eds.) (2010). Coligaçôes Partidárias na Nova Democracia Brasileira: Perfis e Tendências. São Paulo: Universidade Estadual Paulista; Rio de Janeiro: Fundação Konrad Adenauer.

Krause, S., Machado, C. y Miguel, L. F. (coords.) (2016). Coligações e disputas eleitorais na Nova República: aportes teórico-metodológicos, tendências e estudos de caso. São Paulo: Universidade Estadual Paulista; Rio de Janeiro: Fundação Konrad Adenauer.

Laakso, M. y Taagepera, R. (1979). 'Effective' Number of Parties. A Measure with Application to West Europe. Comparative Politcal Studies, 12(1), 3-27. Disponible en: https://doi. org/10.1177/001041407901200101.

Laver, M. y Schepsle, K. (1996). Making and breaking governments: cabinets and legislatures in parliamentary democracies. New York: Cambridge University Press. Disponible en: https://doi.org/10.1017/CBO9780511625671.

Leiras, M. (2007). Todos los caballos del rey. La integración de los partidos politicos y el gobierno democrático en la Argentina, 1995-2003. Buenos Aires: Prometeo.

Lipset, S. M. y Rokkan, S. (1992). Estructuras de división, sistemas de partidos y alineamientos electorales. En A. Batlle (ed.). Diez textos básicos de ciencia política (pp. 231-273). Barcelona: Ariel.

Lublin, D. (2014). Minority rules. Electoral systems, descentralization and ethnoregional party success. Oxford: Oxford University Press. Disponible en: https://doi.org/10.1093/acprof:oso/9780199948826.001.0001.

Lyne, M. (2008). The Voter's Dilemma and Democratic Accountability: Latin America and Beyond. Pennsylvania: Pennsylvania State University Press.

Machado, A. (2009). Minimum Winning Electoral Coalitions Under Presidentialism: Reality or Fiction? The Case of Brazil. Latin American Politics and Society, 51 (3), 87-110. Disponible en: https://doi.org/10.1111/j.1548-2456.2009.00057.x.

Mainwaring, S. (ed.) (2018). Party Systems in Latin America: Institutionalization, Decay, and Collapse. Cambridge: Cambridge University Press. Disponible en: https://doi. org/10.1017/9781316798553.

Mair, P. y Katz, R. (2015). Los cambios en los modelos de organización y democracia partidaria: la emergencia del partido cartel. En F. Casal Bertóa y G. Scherlis (comps.). Partidos, sistemas de partidos y democracia. La obra esencial de Peter Mair (pp. 23-50). Buenos Aires: Editorial Universitaria de Buenos Aires. 
Malamud, A. (2012). Ni mucho gobierno de la opinión ni tanto regreso de la voluntad: bipartidismo recargado. En A. Malamud y M. De Luca (coords.). La Politica en Tiempos de los Kirchner (pp. 105-114). Buenos Aires: Editorial Universitaria de Buenos Aires.

— y De Luca, M. (2016). ¿ Todo sigue igual que ayer? Continuidad y ruptura en el sistema de partidos argentino (1983-2015). En F. Freidenberg (ed.). Los sistemas de partidos en América Latina 1978-2015. Tomo 2: Cono Sur y Países Andinos (pp. 27-68). México D. F.: Universidad Nacional Autónoma de México; Instituto Nacional Electoral.

Miño, J. A. (2014). El efecto del gobierno dividido vertical sobre la formación de alianzas divergentes en los estados mexicanos, 1994-2003 [tesis de maestría]. México: Facultad Latinoamericana de Ciencias Sociales.

Morgenstern, S. (2017). Are Politics Local? The Two Dimensions of Party Nationalization around the World. Cambridge: Cambridge University Press. Disponible en: https://doi. org/10.1017/9781108227865.

— , Swindle, S. y Castagnola, A. (2009). Party Nationalization and Institutions. Journal of Politics, 71 (4), 1322-1341. Disponible en: https://doi.org/10.1017/s0022381609990132.

Navarro, M. y Varetto, C. (2014). La estructura de competencia partidaria Argentina: análisis y evaluación de la imagen analítica de la "territorialización» del sistema de partidos. Revista Chilena de Derecho y Ciencia Política, 5 (1), 109-147.

Pallarés, F. y Keating, M. (2003). Multi-level Electoral Competition: Regional Elections and Party Systems in Spain. European Urban and Regional Studies, 10 (3), 239-255. Disponible en: https://doi.org/10.1177/09697764030103005.

Panebianco, A. (1990). Modelos de partidos. Organización y poder en los partidos politicos. Madrid: Alianza.

Reniu, J. M. (2008). Los gobiernos de coalición en los sistemas presidenciales de Latinoamérica. Elementos para el debate. Documentos CIDOB, 25. Barcelona: Fundación CIDOB.

— y Albala, A. (2012). Los gobiernos de coalición y su incidencia sobre los presidencialismos latinoamericanos: el caso del Cono Sur. Revista de Estudios Políticos, 26, 161-214. Disponible en: https://doi.org/10.22201/fcpys.24484903e.2012.26.31965.

Reynoso, D. (2011). La estrategia dominante. Alianzas electorales en los estados mexicanos 19882011. Buenos Aires: Teseo; Facultad Latinoamericana de Ciencias Sociales.

— y Espinosa Santiago, O. (coords.) (2017) ¿Alianzas contra natura o antihegemónicas? Las alianzas PAN-PRD en los Estados mexicanos. México D. F.: Tirant Lo Blanch; Benemérita Universidad Autónoma de Puebla.

— y Miño, J. A. (2017). La naturaleza de las alianzas contra natura. En: D. Reynoso y O. Espinosa Santiago (coords.) (2017) ¿Alianzas contra natura o antihegemónicas? Las alianzas PAN-PRD en los Estados mexicanos (pp. 33-63). México D. F.: Tirant Lo Blanch; Benemérita Universidad Autónoma de Puebla.

Samuels, D. (2000). The Gubernatorial Coattails Effect: Federalism and Congressional Elections in Brazil. Journal of Politics, 62, 240-253. Disponible en: https://doi. org/10.1111/0022-3816.00012.

Schakel, A. H. y Jeffery, C. (2013). Are Regional Elections really 'Second-Order' elections? Regional Studies, 47 (3), 323-341. Disponible en: https://doi.org/10.1080/00343404.2 012.690069 . 
Serrafero, M. D. (2006). Coaliciones de gobierno: entre la ingeniería institucional y la civilización política. Anales de la Academia Nacional de Ciencias Morales y Politicas, 33.

Stefuriuc, I. (2009). Government Formation in Multi-Level Settings: Spanish Regional Coalitions and the Quest for Vertical Congruence. Party Politics, 15 (1), 93-115. Disponible en: https://doi.org/10.1177/1354068808097895.

Suárez Cao, J., Batlle, M. y Wills-Otero, L. (2017). El auge de los estudios sobre la política subnacional en Latinoamérica. Revista Colombia Internacional, 90 (abril-junio), 15-34. Disponible en: https://doi.org/10.7440/colombiaint90.2017.01.

Swenden, W. y Maddens, B. (2009). Territorial Party Politics in Western Europe. Basingstoke: Palgrave Macmillan.

Thorlakson, L. (2013). Measuring vertical integration in parties with multi-level systems data. PartyPolitics, 19(5),713-734.Disponibleen:https://doi.org/10.1177/1354068811411024.

Torcal, M. (coord.) (2015). Sistemas de partidos en América Latina. Causas y consecuencias de su equilibrio inestable. Barcelona: Anthropos Editorial; Santa Fe (Argentina): Universidad Nacional del Litoral.

Tsebelis, G. (1990). Nested Games. Rational Choice in Comparative Politics. Berkely: California University Press.

Vommaro, G. (2017). La larga marcha de Cambiemos. La construcción silenciosa de un proyecto de poder. Buenos Aires: Siglo xxi.

Wilson, A. (2009). Multi-level Party Politics in Italy and Spain [tesis doctoral]. European University Institute. Disponible en: https://bit.ly/2OCQnX7.

Zelaznik, J. (2001). The Building of Coalitions in the Presidential Systems of Latin America: an Inquiry into the Political Conditions of Governability [tesis doctoral]. University of Essex.

- (2012). Materiales para el estudio del sistema político argentino (1999-2011). En A. Malamud y M. De Luca (coords.). La Política en Tiempos de los Kirchner (pp. 277-328). Buenos Aires: Editorial Universitaria de Buenos Aires.

- (2013). Unión Cívica Radical: entre el Tercer Movimiento Histórico y la lucha por la subsistencia. Revista SAAP: Sociedad Argentina de Análisis Politico, 7 (2), 423-431. 